\title{
Variation of Erythroid and Myeloid Precursors in the Marrow and Peripheral Blood of Volunteer Subjects Infected with Human Parvovirus (B19)
}

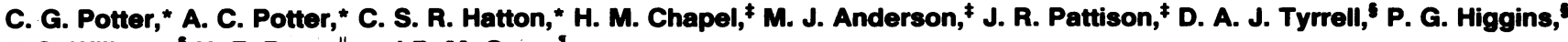 \\ J. S. Willman," H. F. Parry," and P. M. Cotes" \\ ${ }^{*}$ Nuffield Department of Clinical Medicine, and ${ }^{\ddagger}$ Department of Immunopathology, John Radcliffe Hospital, Headington, Oxfordshire \\ OX3 9DU United Kingdom; ${ }^{\ddagger}$ Department of Medical Microbiology and the Middlesex Hospital Medical \\ School, Faculty of Clinical Sciences, University College, London WC1E 6JJ United Kingdom; ${ }^{\S}$ Medical Research Center Common Cold \\ Unit, Harvard Hospital, Salisbury, Wiltshire SP2 8BW United Kingdom; "Department of Haematology, Salisbury General Hospital, \\ Salisbury, Wiltshire SP2 7SX United Kingdom; and 'Section of Haematology, Clinical Research Centre, Harrow, Middlesex HA1 3 UJ \\ United Kingdom
}

\begin{abstract}
Infection of normal individuals with human parvovirus (B19) results in a mild disease (erythema infectiosum) but gives rise to aplastic crises in patients with chronic hemolytic anemias. The effects of this disease on hemopoiesis were investigated following intranasal inoculation of the virus into three volunteers. A typical disease ensued with a viremia peaking at $9 \mathrm{~d}$. Marrow morphology $6 \mathrm{~d}$ after inoculation appeared normal but at $10 \mathrm{~d}$ there was a severe loss of erythroid precursors followed by a 12-g drop in hemoglobin, and an increase in serum immunoreactive erythropoietin. Erythroid burst-forming units (BFU-E) from the peripheral blood were considerably reduced, starting at the time of viremia and persisting for 4-8 d depending on the individual. Granulocyte-macrophage colony-forming units (CFU-GM) were also affected but the loss started $2 \mathrm{~d}$ later. Both CFU-GM and BFU-E showed a sharp overshoot at recovery. In the marrow, BFU-E and CFU-E were reduced at 6 and $10 \mathrm{~d}$ in the individual having the longest period of peripheral progenitor loss. In contrast, there was an increase in BFU-E and CFU-E in the subject with least change in peripheral progenitors. In the third subject, with an intermediate picture, there was a loss at $6 \mathrm{~d}$ but an increase at $\mathbf{1 0} \mathrm{d}$ of erythroid progenitors. It is suggested that the architecture of the marrow might partially isolate progenitors from high titers of virus in the serum and individual variation in this respect might give the results observed.
\end{abstract}

\section{Introduction}

Human parvovirus (1) (B19) is the cause of erythema infectiosum (fifth disease) $(2,3)$, which is a common illness of childhood but also occurs in adults. After an incubation period of 5-7 d there is a prodromal phase characterized by headache, malaise, pyrexia, and respiratory symptoms associated with a high viremia. This is frequently followed a week or so later by a rash and a typically transient arthralgia. In adults the later symptoms occur more commonly in women (4).

\footnotetext{
Address reprint requests to Dr. C. G. Potter.

Received for publication 16 June 1986 and in revised form 20 January
} 1987.

J. Clin. Invest.

(c) The American Society for Clinical Investigation, Inc.

0021-9738/87/05/1486/07 \$1.00

Volume 79, May 1987, 1486-1492
Infection with B19 results in aplastic crises in individuals with chronic hemolytic anemia due to sickle cell disease $(5,6)$, beta thalassemia (7), pyruvate kinase deficiency (8), and hereditary spherocytosis (9). The shortened red cell survival in these cases, combined with a temporary cessation of erythropoiesis produced by B19 infection, results in severe anemia.

In a volunteer study, the disease was successfully transmitted to susceptible individuals by intranasal inoculation of virus (10). The typical mild symptoms occurred and immediately after the viremia there was a reproducible pattern of hematological changes in reticulocyte count and hemoglobin, consistent with the changes observed in the B19-induced aplastic crises. In addition, there was a loss of platelets and myeloid elements from the peripheral blood that ranged from 30 to $70 \%$ of baseline levels although these transient decreases, like those of the erythrocytes, are not hazardous in normal individuals.

The changes in peripheral blood counts have been assumed to originate from the effects of the virus on the bone marrow precursors. Study of normal bone marrow in vitro has shown that the late erythroid precursors (erythroid colony forming units, CFU-E ${ }^{1}$ ) are sensitive to virus-containing serum whereas the more primitive precursors (erythroid burst-forming units BFUE), are also sensitive but to a lesser extent $(11,12)$. It has been shown that these cells may be a site of viral reproduction by taking BFU-E after $8 \mathrm{~d}$ growth, exposing them to virus and replating. Following a further $8 \mathrm{~d}$ in vitro small colonies grew, in which some of the cells were shown to contain crystalline arrays of virus within the nucleus (13). It was therefore decided to conduct a further volunteer study to examine the erythroid and myeloid precursors in both the peripheral blood and the bone marrow of subjects experimentally infected with B19 and to investigate changes in serum erythropoietin to establish whether the viral infection was associated with impaired secretion of the hormone. This paper describes these results and relates them to the time course of the virological events and to the hematological changes that occurred.

\section{Methods}

Volunteers and the B19 infection protocol. Three healthy male subjects (hereafter A, B, and C) aged 38, 33, and $36 \mathrm{yr}$, respectively, whose serum contained no detectable antibodies to B19, were selected from a panel of volunteers who had shown their willingness to take part in trials at the Common Cold Unit, Salisbury. All were given clinical, biochemical, and hematological examinations and a chest $\mathrm{x}$-ray and were found to

1. Abbreviations used in this paper: BFU-E, erythroid burst-forming units; CFU-E, erythroid colony-forming units; CFU-GM, CFU-granulocyte macrophage; CRP, C-reactive protein. 
be normal. The procedures involved and the possible symptoms were described and each volunteer gave assent. Ethical permission was obtained from the Ethical Committee of Northwick Park Hospital, Harrow.

Venous blood samples were taken from the volunteers on arrival to obtain baseline values. The following day these were repeated and the subjects were infected by inoculating into each nostril, $0.5 \mathrm{ml}$ of a $1 \%$ dilution in saline of infectious serum containing $\sim 10^{10}$ genomes B19/ $\mathrm{ml}$. This was the same serum as used in the previous trial (10) and was obtained from a symptom-free blood donor. Thereafter, samples of gargles, throat swabs, and venous blood were obtained at frequent intervals. Bone marrow was aspirated from the iliac crest of each subject under local anesthetic, on three occasions, at times calculated to coincide with the start and end of the viremic phase, as well as a postrecovery (control) sample at $70 \mathrm{~d}$. The subjects were examined clinically each day, the oral temperature self-recorded, and a symptom record completed by the clinical observer.

Hematology. Samples of blood were collected into EDTA and counts made using an Ortho ELT 800 (Ortho Diagnostics, Raritan, NJ). Blood films were made within $5 \mathrm{~h}$ and stained with May Grunwald-Giemsa stain. Differential counts were made on 200 cells. Lymphocytes were obtained from each sample and the subsets determined using the antibodies OKT3, OKT4, OKT8, WR-6, and FMC4 in addition to antisera to kappa and lambda light chains.

Marrow aspirates were immediately smeared onto slides and air dried. They were later stained by May Grunwald-Giemsa and differential counts performed on samples of 500 cells.

Virology. Samples of serum, throat swab, and gargle were examined for B19 DNA by dot-blot hybridization using ${ }^{32} \mathrm{P}$-labeled cloned viral DNA and visualized by autoradiography (14). The development of antibody was monitored by measurement of anti-B19 IgM and IgG, as previously described (15).

Immunology. Rheumatoid factor in serum was screened using a latex bead test (Rapitex, Hoescht Corp., Raritan, NJ) followed by a hemagglutination assay (Fujirebio, Inc., Tokyo, Japan). C reactive protein (CRP) was measured by nephelometry using an ICF system (Beckman Instruments, Inc., Fullerton, $C A$ ) and $\beta$-2-microglobulin (18) by radioimmunoassay (RIA) (Pharmacia Fine Chemicals, Piscataway, NJ). Erythropoietin was assayed in the serum samples, which had been stored at $-40^{\circ} \mathrm{C}$, by modification I (16) of a radioimmunoassay for the hormone (17).

Colony assay. Samples of peripheral blood were taken into EDTA and transported to Oxford in a vacuum flask containing water at $37^{\circ} \mathrm{C}$. $3 \mathrm{~h}$ after each sampling the blood was spun down over Ficoll (Lymphoprep, Nygaard, Norway), washed twice in RPMI medium (Northumbria Biologicals, Cramlington, UK), and the light-density fraction containing mononuclear cells resuspended in alpha modification of Eagle's medium (Northumbria Biologicals) with $30 \%$ fetal calf serum (FCS). The cells were counted in a hemocytometer. Marrow was treated similarly but transported in alpha medium containing $10 \%$ FCS and $5 \mathrm{U} / \mathrm{ml}$ preservative-free heparin. Cultures for growth of BFU-E were set up in $1 \%$ methocel dissolved in alpha medium containing $30 \%$ FCS, $10 \%$ bovine serum albumin (BSA) (Sigma Chemical Co., St. Louis, MO), 1 U/ml sheep erythropoietin (Arnold R Horwell Ltd., London, Connaught Step III) and $10^{-4} \mathrm{M}$ mercaptoethanol. CFU-GM were set up in a similar medium without BSA or erythropoietin but with $6.25 \%$ placental conditioned medium (18) as a source of colony-stimulating factor. Cultures were set up in medium containing either $30 \%$ FCS or $20 \%$ FCS plus $10 \%$ of autologous serum, prepared from a clotted blood sample taken the same day. Cells from peripheral blood were cultured at a density of $3.0 .10^{5} / \mathrm{ml}$ for BFU-E and $3.75 .10^{5} / \mathrm{ml}$ for CFU-GM while marrow cells were plated at a density of $1.10^{5} / \mathrm{ml}$ for BFU-E and $1.25 .10^{5} / \mathrm{ml}$ for CFU-GM. The mixture of cells in methocel was plated out as $0.3-\mathrm{ml}$ cultures in 24-well plates (Falcon Labware, Oxnard, CA) and each well covered with $0.5 \mathrm{ml}$ of light liquid paraffin oil, which acted as a barrier to abrupt changes in $\mathrm{pH}$ and to dehydration (19). The plates were incubated at $37^{\circ} \mathrm{C}$ in glass desiccators gassed with $5 \% \mathrm{CO}_{2}$ in air.

In one experiment, BFU-E were grown from the peripheral blood of a normal individual who was not immune to B19. The cultures included
$10 \%$ (or equivalent) of fractionated or whole viremic sera, taken 6 and $8 \mathrm{~d}$ after infection. $0.5-\mathrm{ml}$ aliquots of serum were fractionated by centrifugation at $180,000 \mathrm{~g}$ for $60 \mathrm{~min}$ at $8^{\circ} \mathrm{C}$ under light liquid paraffin oil. The pellet, diluted to $0.5 \mathrm{ml}$ in Hanks' balanced saline solution, and the supernatant were tested for B19 by dot blot assay. The pellet contained approximately the same amount of viral DNA as the serum source while virus in the serum supernatant was reduced to $<0.5 \%$.

Erythroid colonies were counted at 4, 8, and $12 \mathrm{~d}$ for marrow (20) and $12 \mathrm{~d}$ for peripheral blood. CFU-GM were counted at 12 days for both marrow and peripheral blood. Counting was performed on triplicate myeloid and quadruplicate erythroid culture wells and the total expressed as the number per $10^{5}$ light-density cells plated. Since the errors in this type of experiment are mainly due to the relatively small number of colonies counted and on the precision of the hemocytometer count, the figures show error bars compounded from these two figures assuming that a Poisson distribution is applicable. The relative error is given by: relative error $=\left(1 / n_{1}+1 / n_{2}\right)^{1 / 2}$, where $n_{1}=$ number of cells counted on the hemocytometer and $n_{2}=$ total number of colonies counted. From these errors the significance of differences between samples was calculated.

\section{Results}

Virology. The time course of the viremia and the specific antibody response was similar to that previously described (10). Virus was detected in the serum of two of the volunteers (A and C) from day 6 to day 12 and in the third (B) from day 6 to 10 (Fig. 1). Throat swabs and gargles were also positive at the time of viremia (data not shown). Specific antibody of the IgM class was detectable towards the end of the viremia in all three volunteers and reached maximum concentrations ( $>100$ arbitrary units) by day 14 . All three volunteers also developed specific IgG antibody during the week following the viremia (data not shown).

Clinical features. The subjects showed only the prodromal symptoms expected of infection with B19, although the severity varied. Subject $\mathrm{C}$ was least affected, feeling unwell for only a few hours. Subject A was affected for a day with slight fever $\left(38^{\circ} \mathrm{C}\right)$ while subject B had a similar fever but was confined to bed for $7 \mathrm{~h}$ on one day and for $2 \mathrm{~h}$ the next. The severity of these symptoms was not related to the maximum titers of virus, which varied little in the three subjects, nor to the hematological changes. Thereafter the subjects remained symptom free for the duration of the trial. No rash or arthralgia occurred and rheumatoid factor in the serum did not increase above the background level. CRP values were raised slightly in two of the subjects at the time of the peak viremia but became undetectable for the remainder of the trial. CRP and rheumatoid factor also remained low in the samples taken at the $70 \mathrm{~d}$ followup and no late clinical sequelae were noted. $\beta$-2-Microglobulin (Fig. 1) showed an increase at the same time as the loss of platelets and neutrophils but returned slowly to baseline after a few days as the cells recovered.

Hematology. The numbers of platelets, lymphocytes, and neutrophils, together with hemoglobin values, are shown for each subject in Fig. 1. Hemoglobin fell by $2-3 \mathrm{~g} / 100 \mathrm{ml}$ over the period of the trial, more rapidly after development of the viremia. Lymphocyte numbers showed a sharp fall at the time of maximum viremia while platelet and neutrophil counts also fell but a day or so later. The three subjects varied a little in the extent and timing of the hematological changes produced by the disease. In subject $A$ the changes for each cell type occurred about $2 \mathrm{~d}$ later and his platelets and leukocytes were a little less affected than those of the other two subjects. In all three subjects the number of lymphocytes fell $2 \mathrm{~d}$ before the decline in platelet 

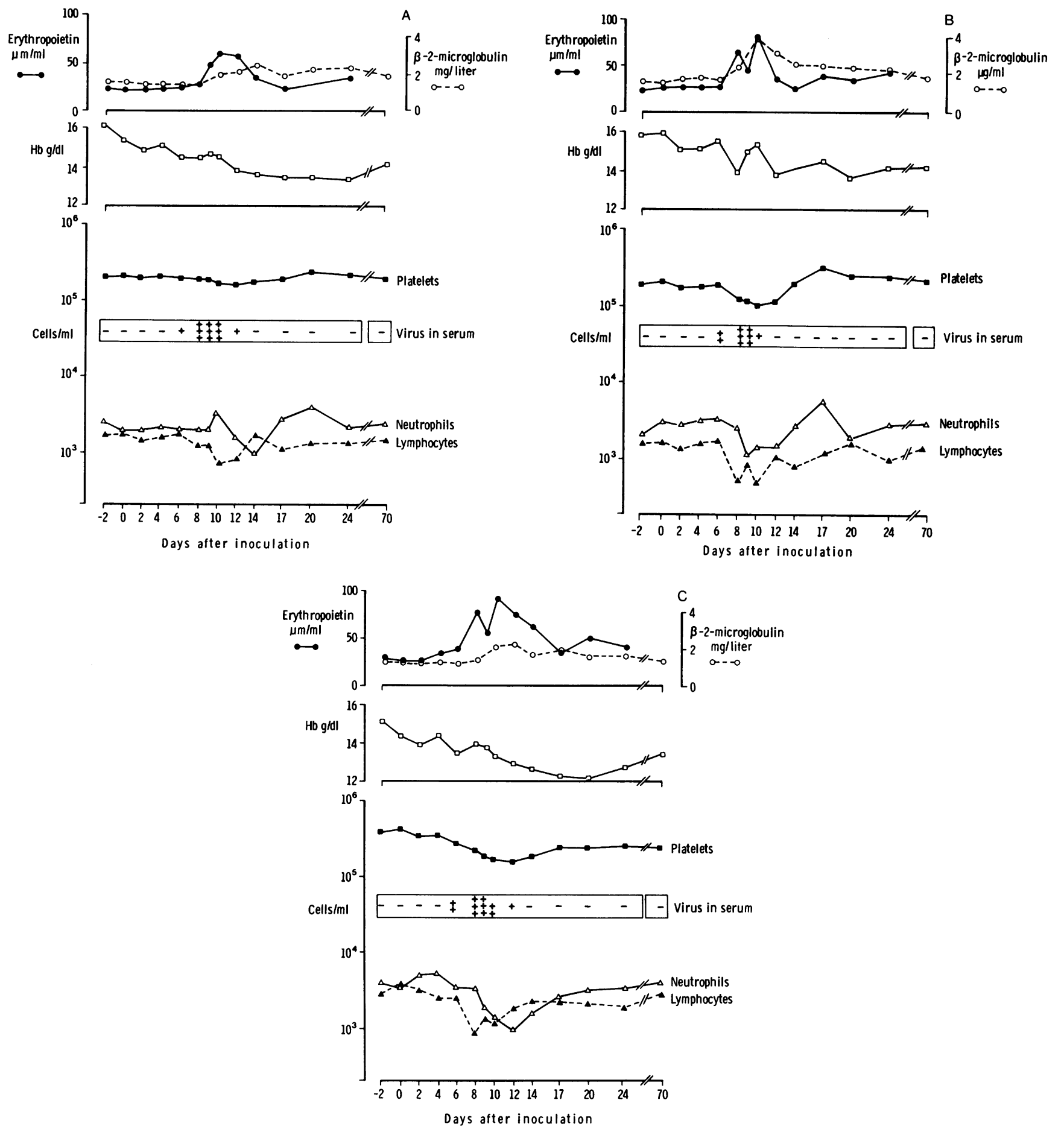

Figure 1. Hematological data for each of the three subjects, shown with $\beta$-2-microglobulin and erythropoietin data.

and white counts. The lymphocyte subset data showed that the absolute numbers of both helper and suppressor $\mathrm{T}$ cells were equally reduced at the time of the viremia. Recovery of lymphocyte counts was prompt, occurring as soon as the virus was cleared from the serum, whereas neutrophils recovered a few days later, sometimes exhibiting a transient overshoot above baseline values. Hemoglobin in the subjects $A-C$, recovered at 67,41 , and $24 \mathrm{~d}$, respectively, after inoculation with the virus. The rate of recovery did not appear to correlate with the severity of thrombocytopenia and leukopenia or with clinical symptoms.
The bone marrow differential counts are shown in Table I. The morphology of the day 6 marrows were similar to those of the control subjects at $70 \mathrm{~d}$ although some of the erythroid precursors in the day 6 marrow were slightly macronormoblastic with cytoplasmic vacuolation. Marrow samples after transportation and processing showed good cellular morphology before culturing. In the day 10 marrow there was an almost total loss (to $<3 \%$ ) of erythroid cells at all stages of development. The remaining myeloid cells were in the proportions expected if the erythroid component alone had been lost; their morphology was 
Table I. Differential Counts (\% 500 Cells) of Marrows Taken from Subjects at 6, 10, and 70 d after Inoculation with B19

\begin{tabular}{|c|c|c|c|c|c|c|c|c|c|}
\hline \multirow{2}{*}{$\begin{array}{l}\text { Time after inoculation } \\
\text { Individual }\end{array}$} & \multicolumn{3}{|l|}{$6 \mathrm{~d}$} & \multicolumn{3}{|c|}{$10 \mathrm{~d}$} & \multicolumn{3}{|c|}{$70 \mathrm{~d}$} \\
\hline & A & B & C & A & B & C & A & B & C \\
\hline Normoblasts & 30 & 27 & 41 & 1 & 0 & 2 & 30 & 36 & 33 \\
\hline Myeloid cells & 55 & 56 & 52 & 77 & 82 & 83 & 58 & 50 & 57 \\
\hline Lymphocytes & 8 & 12 & 4 & 16 & 13 & 9 & 10 & 12 & 8 \\
\hline Other & 7 & 5 & 3 & 6 & 5 & 6 & 2 & 2 & 2 \\
\hline
\end{tabular}

normal although there were a number of large cells with uniform nuclei and large cytoplasmic/nuclear ratios. This description is consistent with their being large atypical lymphocytes or possibly proerythroblasts.

Erythropoietin. Each of the serum samples from the three subjects was assayed for erythropoietin and the results are shown in Fig. 1. In each case the erythropoietin shows a sharp increase after the peak viremia, which coincided with the loss of erythroid precursors in the bone marrow. The erythropoietin concentration then declined towards base line values by 14 or $17 \mathrm{~d}$ after infection, which was when the numbers of BFU-E in the peripheral blood had recovered but while $\mathrm{Hb}$ values remained depressed. A secondary rise in serum erythropoietin occurred at 20-23 d.

$B F U-E$ and $C F U-G M$ in blood. Fig. 2 shows the results of the growth of BFU-E and CFU-GM from the peripheral blood of the three subjects. There is an initial phase, before development of the viremia, when the number of BFU-E remained similar to base line values. At the onset of the viremia the number of colonies fell to a very low level. The number rose at the end of the viremic phase with a marked overshoot, before returning to the baseline values at recovery. The general similarity in the number of colonies in cultures grown with $30 \%$ FCS or with $20 \%$ FCS plus $10 \%$ autologous serum, indicates the reproducibility of the techniques used. Only in one sample (day 8 , subject A) was there a profound inhibitory effect of autologous serum on BFU-E. CFU-GM were greatly decreased in a similar pattern to that of the BFU-E although the fall occurred $2 \mathrm{~d}$ later, coinciding with the time of maximum viremia. In some of the BFU$\mathrm{E}$ or CFU-GM cultures there was some increase in colony numbers in the presence of autologous serum, indicating a stimulatory effect, especially during the recovery phase at the time of the overshoot.

Table II shows the results when whole serum, serum supernatant and viral pellet were added at $10 \% \mathrm{vol} / \mathrm{vol}$ (or equivalent) to BFU-E cultures of peripheral blood taken from a different, nonimmune subject. Wherever there was a high degree of viremia $(+++)$ then both the viral pellet and whole serum produced a profound inhibition in colony numbers. At lower titers the virus was diluted enough to have little effect and these results are comparable with previous in vitro experiments. Supernatants, with $<0.5 \%$ of the viral content of whole serum, produced no inhibition and may have had some stimulatory effect.

$B F U-E, C F U-E$, and $C F U-G M$ in marrow. A more complicated situation obtained for the numbers of erythroid colonies grown from the marrow (Fig. 3). In subject A, 4-d CFU-E in the first marrow were greatly increased but 8-d CFU-E and BFU$E$ were similar to controls taken at $70 \mathrm{~d}$. In the second marrow, taken at the time of maximum viremia and greatest loss of progenitors from the peripheral blood, there were more erythroid progenitors of all stages than in the control. In subjects B and $\mathrm{C}$, the 6-d marrows showed a reduction in BFU-E and 8-d CFU$E$ but not in 4-d CFU-E. In the second marrow of $B$, the numbers of BFU-E and $8 \mathrm{~d}$ CFU-E were raised but not $4 \mathrm{~d} C F U-E$, whereas for subject $\mathrm{C}$ a quite different pattern was observed, since all the erythroid progenitors were reduced.

The number of CFU-GM in the marrow of subjects $A$ and B were increased in the first sample compared with the 70-d control samples but in subject $C$ there was a small decrease. In the second marrow, CFU-GM were increased only in subject B while remaining reduced in subject $C$. These changes were of much smaller magnitude than those of the erythroid progenitors.

Where high titers of virus were present, growth of erythroid progenitors was considerably inhibited by inclusion of $10 \%$ autologous serum. There was no inhibition of CFU-GM by such sera although in some cultures there was evidence of a stimulatory effect (data not shown).

\section{Discussion}

The timing of both the transient appearance of virus in throat samples and the seroconversion for viral-specific IgM and IgG in all three subjects was similar to that observed in the previous volunteer study, as were the minor clinical and hematological changes occurring at the time of the viremia (10). No rash or arthralgia was observed and there were minimal alterations of circulating CRP and rheumatoid factor. The increased $\beta-2-\mathrm{mi}-$ croglobulin coincided with the loss of neutrophils and platelets and it could have been released by damage of these cells. If so, this might indicate that the previous fall in lymphocyte count was not due to damage but perhaps to sequestration of these cells elsewhere in the body.

In contrast to the generally mild clinical and hematological effects of the B19 infection, the marrow samples taken on the 10th day after inoculation showed an almost total absence of erythroid precursors. This loss could be either some indirect effect of the infection or a direct damaging effect of the virus upon progenitors, resulting in aplasia by loss of production of mature elements that might also be damaged directly by the virus. One possible indirect effect was investigated by estimation of erythropoietin in the serum. This showed a moderate increase (in contrast to the 100-fold increase common in aplastic anemia) at the time of erythroid aplasia, suggesting that this was secondary to and not a cause of the anemia. Serum erythropoietin peaked before the nadir in hemoglobin and increased again at 20-23 d suggesting that erythroid end-cell mass and oxygenation were not the only factors involved in regulation of the hormone. Indeed the changes in erythropoietin were more nearly inversely related to the presence of red cell progenitors and might reflect erythropoietin binding to receptors.

It was also possible that serum inhibitors might be present during the viremia and produce part or all of the changes observed. $\alpha$-Interferon might act in this way but was not detected in serum taken during the previous volunteer study (10), while inhibitory effects of viremic serum in vitro were not abolished by its prior treatment with antiinterferon antibodies (12). We have shown that the in vitro inhibition of BFU-E produced by highly viremic serum also occurred with the viral pellet but not with serum freed of virus by centrifugation, demonstrating a probable lack of any inhibitors in the unfractionated viremic serum samples, other than the virus. 

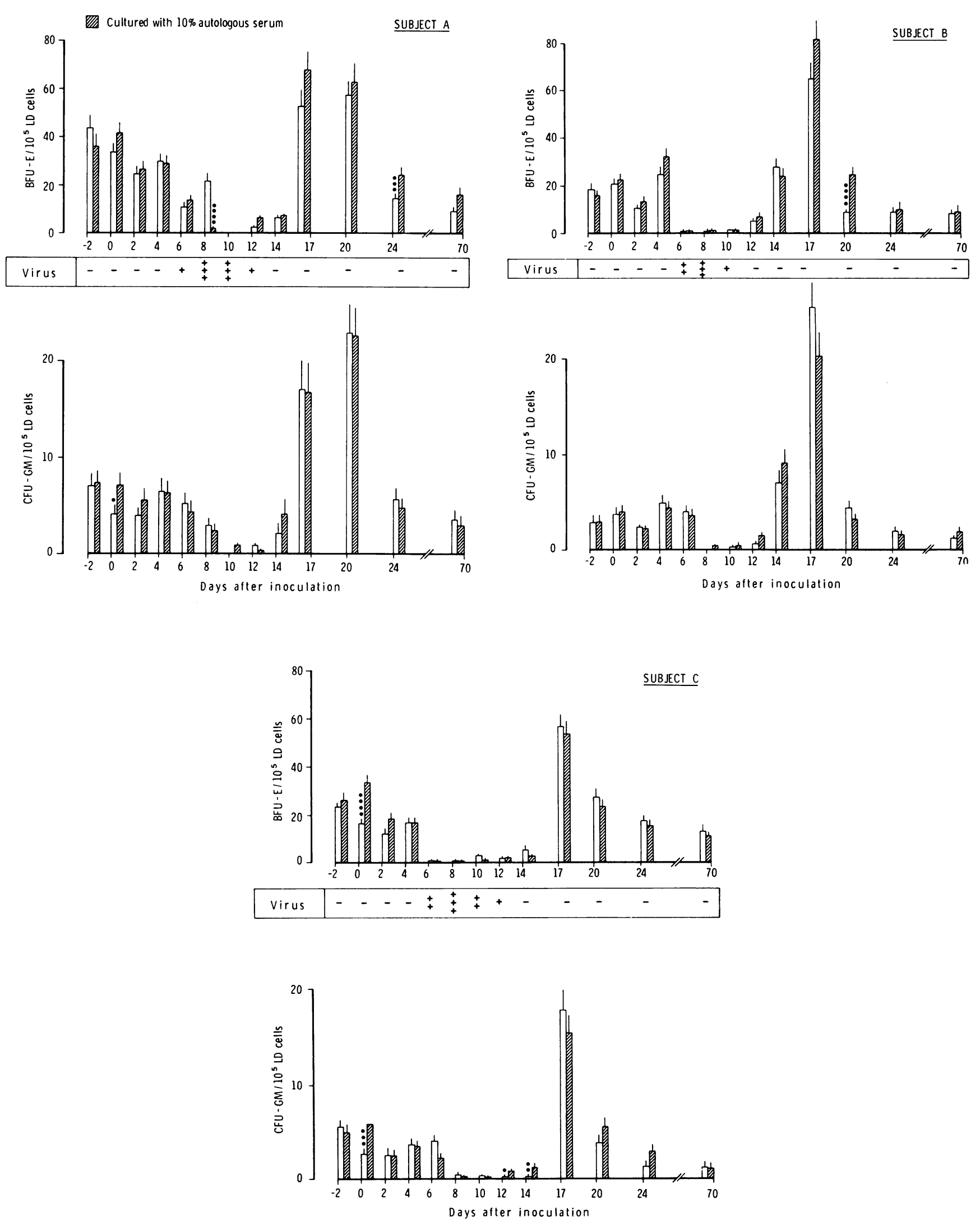

Figure 2. Growth of BFU-E and CFU-GM from the peripheral blood of the three subjects at different times after inoculation with B19. (Open bars) BFU-E grown with 30\% FCS, (cross-hatched bars) with $20 \%$ FCS and $10 \%$ autologous serum. Error bars give SE values calcu- lated from the combination of hemocytometer and colony counts. Significance between samples with and without inclusion of $10 \%$ autologous serum are denoted: ${ }^{*} 0.05>P>0.02,{ }^{* *} 0.02>P>0.01$, ${ }^{* * *} 0.01>P>0.001,{ }^{* * * *} 0.001>P$. 
Table II. Effect of Viremic Serum and Serum Fractions on BFU-E Grown from the Peripheral Blood of a Nonimmune Donor

\begin{tabular}{|c|c|c|c|c|c|}
\hline \multirow[b]{2}{*}{ Subject } & \multirow[b]{2}{*}{ Day* } & \multirow[b]{2}{*}{$\begin{array}{l}\text { Serum virus } \\
\text { (dot blots) }\end{array}$} & \multicolumn{3}{|c|}{ Number of BFU-E/10 $(\mathrm{SE})^{*}$} \\
\hline & & & $\begin{array}{l}\text { Whole } \\
\text { serum }\end{array}$ & $\begin{array}{l}\text { Pellet } \\
\text { (virus) }\end{array}$ & $\begin{array}{l}\text { Serum } \\
\text { supernate }\end{array}$ \\
\hline \multirow[t]{3}{*}{ A } & 2 & - & $6.7(2.1)$ & - & - \\
\hline & 6 & +++ & 0 & 0 & $17.1(3.5)$ \\
\hline & 8 & +++ & 0 & 0 & $6.1(2.0)$ \\
\hline \multirow[t]{3}{*}{ B } & 1 & - & $4.3(1.7)$ & - & - \\
\hline & 6 & +++ & 0 & 0 & $6.1(2.0)$ \\
\hline & 8 & + & $1.8(1.0)$ & $6.7(2.1)$ & $4.3(1.7)$ \\
\hline \multirow[t]{3}{*}{ C } & 1 & - & $6.7(2.1)$ & - & - \\
\hline & 6 & +++ & 0 & 0 & $12.2(2.9)$ \\
\hline & 8 & ++ & $2.4(1.2)$ & $15.3(3.3)$ & $14.7(3.2)$ \\
\hline
\end{tabular}

* Serum samples from days 1 and 2 were before inoculation with B19. ${ }^{\ddagger}$ Duplicate wells each containing $8.2 \times 10^{4}$ mononuclear cells. Errors calculated from the combination of hemocytometer and colony counts (see Methods).

${ }^{8}$ Contained no more than $0.5 \%$ virus (by dot blot assay) compared with serum before fractionation.

Direct effects of the virus were investigated by determining the numbers of erythroid and myeloid progenitors in the peripheral blood and bone marrow during the course of the infection. There was a dramatic loss of both erythroid and myeloid progenitors in the peripheral blood at the height of the viremia, while in the marrow changes were restricted to the erythroid lineage. Loss of peripheral erythroid progenitors cannot be easily explained by a cell-specific infection, accompanied by viral replication and cell lysis, since very few of these cells are in S-phase and DNA synthesis of the host cell is thought to be a prerequisite for $\mathrm{B} 19$ as well as animal parvoviruses. It was possible that progenitors were still present, although undetectable, if virus had been carried over into culture and had only become infective when the cells entered S-phase. This cannot be an exclusive explanation because on day 14 the numbers of peripheral BFU-E in all three subjects were low despite there being no detectable circulating virus. In addition, BFU-E from subject $A$ on day 6 , which had been immersed previously in virus-containing serum in vivo, were able to grow in vitro. The density gradient separation and subsequent washes presumably freed the cells of virus. This also indicated that the binding affinity was low, which is unusual for the virus/receptor interaction expected in a cellspecific infection.

Progenitors might be affected by a nonspecific viral cytotoxicity, independent of replication, which could explain the platelet and leukocyte losses observed. CFU-GM were also reduced in the peripheral blood but $2 \mathrm{~d}$ later than the loss of BFU-E. This delay could be explained if CFU-GM were less sensitive than BFU-E to the virus, only being affected at the peak of the viremia. This would imply that CFU-GM might be inhibited at high enough titers in vitro and this is the case with $10^{10-11}$ genomes/ $\mathrm{ml}$ (Potter, C. G., and A. C. Potter, unpublished observations).

The results of the bone marrow colony cultures were difficult to interpret. Sample times were chosen on the basis of peripheral blood and viral findings from a prior volunteer study; however, with only two marrows taken at the time of the viremia, any attempt at reconstructing the events occurring in the bone mar- row during B19 infection can only be tentative, since significant effects of the virus on marrow progenitors may have occurred before and after the samples were taken. The increased colony number observed in some samples could therefore represent transient overshoot phenomena taking place at the progenitor level during recovery. The data showed however that CFU-GM in vivo were relatively insensitive to $B 19$ infection, whereas the effects on BFU-E varied widely between samples and between subjects. Surprisingly, in some marrow samples there was a considerable increase in numbers of erythroid progenitors at a time when viral titers in the serum were very high and mature erythroid elements were absent from the marrow. One possible explanation would be that infection of host cells might hamper growth and possibly block DNA synthesis. The large cells noticed in the marrows at day 10 and described in an early study of aplastic crisis in hereditary spherocytosis (21) are consistent with the concept of a blockade of DNA synthesis and/or differentiation.

The profound inhibitory effect of $10 \%$ high titer serum in vitro compared with the lesser effect on the marrow in vivo might be explained by considering the role of the sinusoidal endothelial lining of the marrow. This lining could provide a

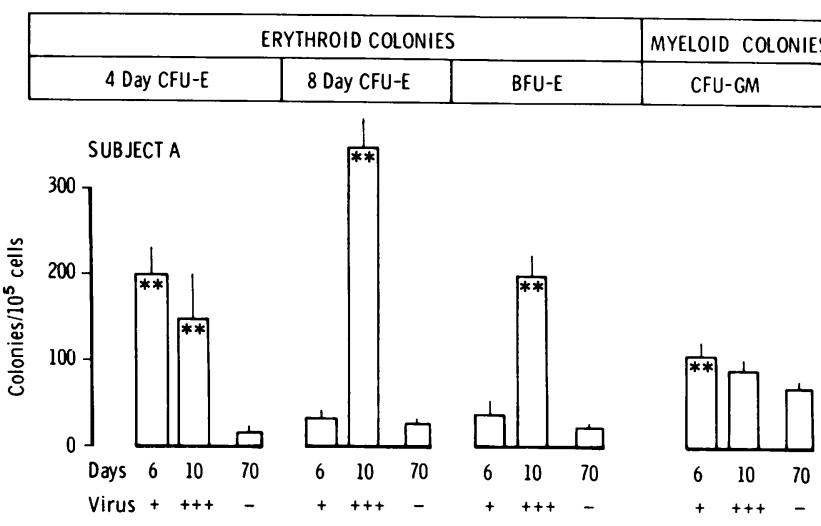

SUBJECT B
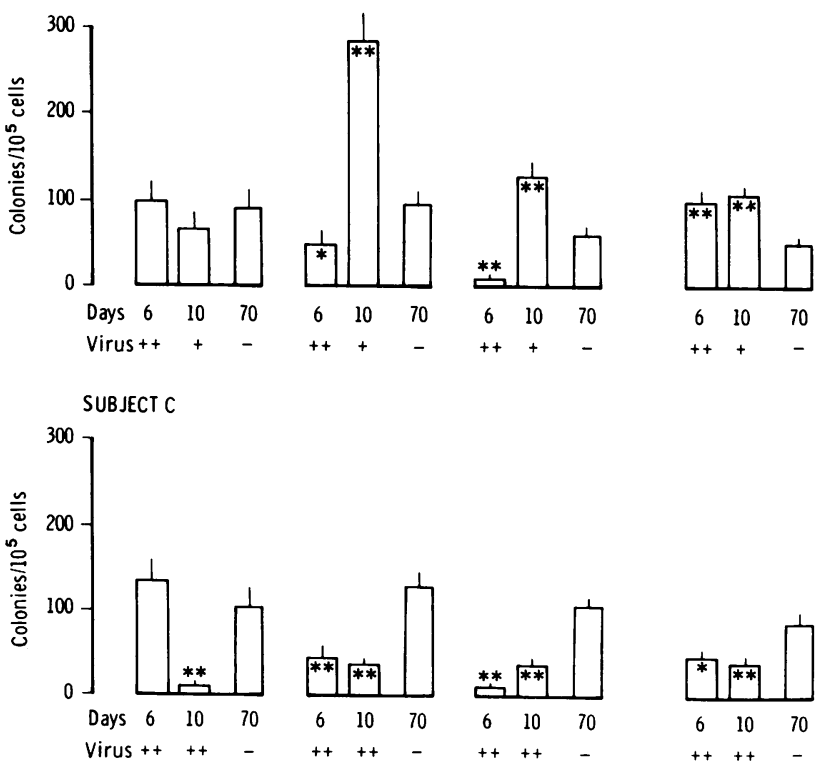

Figure 3. Growth of CFU-E ( $4 \mathrm{~d}$ and $8 \mathrm{~d}$ ), BFU-E, and CFU-GM from the marrows of the three subjects at 6,10 , and $70 \mathrm{~d}$ after inoculation with B19. Significance between 6-d or 10-d samples and 70-d controls are denoted: ${ }^{*} 0.01>P>0.001,{ }^{* *} 0.001>P$. 
partial barrier to B19 reducing the concentration of particles within the parenchyma to a level that might produce a widespread but reversible inhibition with perhaps only a small loss of progenitors. Release of marrow cells from the microenvironment by manipulation in vitro and exposure to the high titers of virus would give the results obtained. Individual differences in the capability of the marrow structure to isolate progenitors from virus in the serum might result in different degrees of erythroid aplasia in different subjects.

Despite these studies, therefore, the pathophysiology of the anemia remains unclear, in particular it is not known whether the erythroid lineage is the major site of viral replication in vivo although in vitro experiments suggest that 8-d CFU-E are prime candidates (13). It can be estimated that a total of $\sim 10^{14}$ viral genomes can be present in the serum while the bone marrow probably contains $\sim 10^{10} \mathrm{CFU}-\mathrm{E}$ in all (22). This would give $10^{4-5}$ particles per cell, which is a high copy number compared with many viruses. However, for the parvovirus that produces Aleutian Disease of mink, in situ hybridization experiments (23) indicate that such a number per cell is not unreasonable. It has been shown recently that in vitro replication of B19 occurs in the highly erythroid bone marrow derived from patients with hemolytic anemias (24). The marrows were cultured with erythropoietin and upon infection produced large numbers of viral particles and became depleted of erythroid precursors. In situ experiments indicated that late erythropoietin-responsive progenitors were target cells in this system. Although knowledge of the natural history of B19 is beginning to emerge, it is still not clear as to the exact mechanisms involved in erythroid aplasia of the marrow and the loss of leukocytes and progenitors from the peripheral blood. The route from initial infection, presumably through the nasopharynx, to the marrow is also unknown and the replication kinetics of this virus which produces such a massive viremia as well as its effect on the marrow therefore warrant further study.

\section{Acknowledgments}

We wish to thank S. E. Jones, I. M. Kidd, and T. W. Lee for carrying out antibody and hybridization assays, Dr. N. O'Connor for taking marrow, Mrs. V. Spriggs for CRP, rheumatoid factor, and $\beta$-2-microglobulin assays. We thank the Blood Diseases Branch of the National Heart Lung and Blood Institutes of Health, Bethesda, MD, for erythropoietin used to prepare radioiodinated tracer and the World Health Organization for the International Reference Preparation of Erythropoietin. We thank R. C. Tam for skilled technical help with the erythropoietin assays. We wish to thank the volunteers for their willing and patient cooperation.

Part of this work was funded by the Wellcome Trust and part by the National Fund for Research into Crippling Diseases.

\section{References}

1. Cossart, Y. E., A. M. Field, B. Cant, and D. Widdows. 1975. Parvovirus-like particles in human sera. Lancet. i:72-73.

2. Anderson, M. J., S. E. Jones, S. P. Fisher-Hoch, E. Lewis, S. M. Hall, C. L. R. Bartlett, B. J. Cohen, P. P. Mortimer, and M. S. Pereira. 1983. Human parvovirus, the cause of erythema infectiosum (fifth disease)? Lancet. i:1378.

3. Plummer, F. A., G. W. Hammond, K. Forward, L. Sekla, L. M. Thompson, S. E. Jones, I. M. Kidd, and M. J. Anderson. 1985. An erythema infectiosum-like illness caused by human parvovirus infection. N. Engl. J. Med. 313:74-79.

4. Reid, D. M., T. M. S. Reid, T. Brown, J. A. N. Rennie, and C. J.
Eastmond. 1985. Human parvovirus-associated arthritis: a clinical and laboratory description. Lancet. i:422-425.

5. Pattison, J. R., S. E. Jones, J. Hodgson, L. R. Davis, J. M. White, C. E. Stroud, and L. Murtaza. 1981. Parvovirus infections and hypoplastic crisis in sickle-cell anaemia. Lancet. i:664-665.

6. Serjeant, G. R., K. Mason, J. M. Topley, B. E. Sergeant, J. R. Pattison, S. E. Jones, and R. Mohamed. 1981. Outbreak of aplastic crises in sickle cell anaemia associated with parvovirus-like agent. Lancet. ii: 595-597.

7. Rao, K. R. P., A. R. Patel, M. J. Anderson, J. Hodgson, S. E. Jones, and J. R. Pattison. 1983. Infection with a parvovirus-like virus and aplastic crisis in chronic hemolytic anemia. Ann. Intern. Med. 98: 930-932.

8. Duncan, J. R., C. G. Potter, M. D. Cappellini, J. B. Kurtz, M. J. Anderson, and D. J. Weatherall. 1983. Aplastic crisis due to parvovirus infection in pyruvate kinase deficiency. Lancet. ii:14-16.

9. Kelleher, J. F., N. L. C. Luban, P. P. Mortimer, and T. Kamimura. 1983. Human serum "parvovirus." A specific cause of aplastic crisis in children with hereditary spherocytosis. J. Pediatr. 102:720-722.

10. Anderson, M. J., P. G. Higgins, L. R. Davis, J. S. Willman, S. E. Jones, I. M. Kidd, J. R. Pattison, and D. A. J. Tyrrell. 1985. Experimental parvovirus infection in man. J. Infect. Dis. 152:257-265.

11. Mortimer, P. P., R. K. Humphries, J. G. Moore, R. H. Purcell, and N. S. Young. 1983. A human parvovirus-like virus inhibits haematopoietic colony formation in vitro. Nature (Lond.). 302:426-429.

12. Young, N. S., P. P. Mortimer, J. G. Moore, and R. K. Humphries. 1984. Characterization of a virus that causes transient aplastic crisis. $J$. Clin. Invest. 73:224-230.

13. Young, N., M. Harrison, J. Moore, P. Mortimer, and R. K. Humphries. 1984. Direct demonstration of the human parvovirus in erythroid progenitor cells infected in vitro. J. Clin. Invest. 74:2024-2032.

14. Anderson, M. J., S. E. Jones, and A. C. Minson. 1985. Diagnosis of human parvovirus infection by dot-blot hybridization using cloned viral DNA. J. Med. Virol. 15:163-172.

15. Anderson, M. J., L. R. Davis, S. E. Jones, and J. R. Pattison. 1982. The development and use of an antibody capture radioimmunoassay for parvovirus specific IgM to a human parvovirus-like agent. J. Hyg. 88:309-324.

16. Cotes, P. M., C. E. Canning, and R. E. Gaines Das. 1983. Modification of a radioimmunoassay for human serum erythropoietin to provide increased sensitivity and investigate non-specific serum responses. In Immunoassays for Clinical Chemistry. W. M. Hunter and J. E. T. Corrie, editors. Churchill Livingstone, Edinburgh. 106-112 and 124127.

17. Cotes, P. M. 1982. Immunoreactive erythropoietin in serum: I. Evidence for the validity of the method and the physiological relevance of estimates. Br. J. Haematol. 50:427-438.

18. Schlunk, T., and M. Schleyer. 1980. The influence of culture conditions on the production of colony-stimulating activity by human placenta. Exp. Hematol. 8:179-184.

19. Potter, C. G., and M. D. Cappellini. 1983. Improved culture of BFU-E and CFU-GM by the use of an oil seal. Br. J. Haematol. 54: 153-154.

20. Ogawa, M., M. D. MacEachern, and L. Avila. 1977. Human marrow erythropoiesis in culture: II. Heterogeneity in the morphology, time course of colony formation, and sedimentation velocities of the colony-forming cells. Am. J. Hematol. 3:29-36.

21. Owren, P. A. 1948. Congenital hemolytic jaundice. The pathogenesis of the "hemolytic crisis." Blood. 3:231-248.

22. Cronkite, E. P., and L. E. Feinendegen. 1976. Notions about human stem cells. Nouv. Rev. Fr. Hematol Blood Cells. 17:269-284.

23. Bloom, M. E., R. E. Race, B. Aaasted, and J. B. Wolfinberger. 1985. Analysis of Aleutian Disease Virus infection in vitro and in vivo. Demonstration of Aleutian Disease Virus DNA in tissues of infected mink. J. Virol. 55:696-703.

24. Ozawa, K., G. Kurtzman, and N. Young. 1986. Replication of the B19 parvovirus in human bone marrow cultures. Science (Wash. DC). 233:883-886. 